\title{
Effects of Fillers on the Damping Property of Ethylene Vinyl-Acetate/Polylactic Acid Blends
}

\author{
Xinyan Shi*, Lingyan Jia, Yan Ma, Chengliang Li \\ Key Laboratory of Rubber-Plastics, Ministry of Education/Shandong Provincial Key Laboratory of Rubber and \\ Plastics, Qingdao University of Science and Technology, Qingdao, China \\ Email: "lindashi88@hotmail.com
}

Received 18 November 2015; accepted 15 February 2016; published 22 February 2016

Copyright (C) 2016 by authors and Scientific Research Publishing Inc.

This work is licensed under the Creative Commons Attribution International License (CC BY).

http://creativecommons.org/licenses/by/4.0/

c) (i) Open Access

\section{Abstract}

New and high performance damping materials from ethylene vinyl-acetate copolymer (VA content over 40\%, shorted as EVM) and polylactic acid (PLA) blends were prepared with dicumyl peroxide (DCP) as the curing agent and triallyl isocyanurate (TAIC) as the curing coagent. The effects of silica, mesoporous silica and glass beads on the damping of the EVM/PLA blends were examined using a dynamic mechanical analyzer (DMA). The microstructures of the silica, mesoporous silica and glass beads were observed by transmission electron microscope (TEM). The dispersion of the fillers in the matrix was studied using a Rubber Process Analyzer (RPA). The results showed that silica filled blend had an effective damping temperature range (EDTR, $\tan \delta>0.3$ ) of $81^{\circ} \mathrm{C}$, while the mesoporous silica/silica and glass beads/silica filled blends had EDTR of $86^{\circ} \mathrm{C}$ and $85^{\circ} \mathrm{C}$, respectively. Mixtures of mesoporous silica and silica as well as glass beads and silica exhibited a more improved dispersion in the blends than silica alone. Blends filled with mesoporous silica and glass beads retained good mechanical properties as well as improved damping performance.

\section{Keywords}

EVM 700, PLA, Damping, Silica, Mesoporous Silica, Glass Beads

\section{Introduction}

Vibration often causes undesirable consequences, such as unpleasant motions, noise, and dynamic stresses,

${ }^{*}$ Corresponding author.

How to cite this paper: Shi, S.Y., Jia, L.Y., Ma, Y. and Li, C.L. (2016) Effects of Fillers on the Damping Property of Ethylene Vinyl-Acetate/Polylactic Acid Blends. Journal of Materials Science and Chemical Engineering, 4, 89-96. 
which lead to fatigue and failure of structures, decreased reliability and poor performance [1]. Polymers have been widely applied for achieving acoustic and vibration damping due to their unique combination of low modulus and inherent damping [2]. However, homopolymers usually exhibit effective damping $(\tan \delta>0.3)$ in a narrow temperature range of $20^{\circ} \mathrm{C}-30^{\circ} \mathrm{C}$ around their glass transition temperatures $\left(\mathrm{T}_{\mathrm{g}}\right)$, within which the polymers have pronounced dissipation of the mechanical energy as heat due to the onset of coordinated chain molecular motions [3]. Several methods have been used to modify the dynamic properties of rubbers, for example, blending [4], interpenetrating polymer network blending [5] [6], copolymerization [7]-[9] and the addition of inorganic fillers to the polymer matrix [10] [11].

Ethylene vinyl-acetate copolymers of high vinyl acetate content (EVM) [12]-[14] and polylactic acid (PLA) [15] have abundant ester groups, and can be used as damping materials due to their high $\tan \delta$ values. Furthermore, their $\mathrm{T}_{\mathrm{g}}$ are some $70^{\circ} \mathrm{C}$ apart and blending of EVM and PLA should enable a large effective damping temperature range (EDTR). In this paper, a Haake torque rheometer (Germany) was chosen to blend EVM with PLA, with dicumyl peroxide (DCP) as the curing agent and triallyl isocyanurate (TAIC) as the curing coagent. The effects of inorganic fillers, including silica, mesoporous silica and glass beads, on the mechanical and damping properties, were examined in order to prepare new and better performance damping materials with wider EDTR.

\section{Experimental Part}

\subsection{Main Materials}

Ethylene vinyl acetate copolymer rubber (EVM 700): Levapren 700, VA = 70 wt.\%, Lanxess Deutschland GmbH, Leverkusen, Germany; Polylactic acid (PLA): 2003D, Nature Works, USA; DCP (40\%): Rhenocure VC-40CC,Trialllyl isocyanurate (TAIC), Rhenofit TAIC/s, Polycarbodiimide (PCD): Stabaxol P, all provided by Rhein Chemie (Qingdao, China); Silica: 1165MP, surface area $165 \mathrm{~m}^{2} / \mathrm{g}$, Rhodia, (Qingdao, China); mesoporous silica: surface area $650 \mathrm{~m}^{2} / \mathrm{g}$, made in the laboratory; Glass beads: 3500 mesh, were bought from market.

\subsection{Formula}

EVM 80 phr, PLA 20 phr, PCD 2 phr., Silica 30 phr (or mesoporous silica/silica = 1/6, 30 phr; glass beads/silica = 1/5 $30 \mathrm{phr}$ ); DCP $1 \mathrm{phr}$, TAIC $0.5 \mathrm{phr}$.

\subsection{Sample Preparation}

EVM and PLA were dried for 12 hours at $60^{\circ} \mathrm{C}$ before use. EVM, PLA and fillers were mixed in a HAAKE Rheomix $30000 \mathrm{~S}$ mixer at a rotor speed of $50 \mathrm{rpm}$ for $12 \mathrm{~min}$ at $160^{\circ} \mathrm{C}$. The blends were taken out of the mixer and processed at room temperature with DCP and TAIC on an SK-160B two-roll mill manufactured by Shanghai Plastics and Rubber Machinery Factory, China, and then molded into sheets in a VC-150T-FTMO-3RT vacuum press manufactured by Jiaxin Electric Company, China, at $170^{\circ} \mathrm{C}$ for $10 \mathrm{~min}$.

\subsection{Measurements}

The dynamic mechanical analysis was carried out on a Netzsch DMA 242 Dynamic Mechanical Analyzer, manufactured by Netzsch Company, Germany, using a rectangle sample of $35 \mathrm{~mm} \times 4 \mathrm{~mm} \times 2 \mathrm{~mm}$, from $-60^{\circ} \mathrm{C}$ to $100^{\circ} \mathrm{C}$ at a heating rate of $3 \mathrm{~K} / \mathrm{min}$ and a fixed frequency of $1 \mathrm{~Hz}$ in a mode of double cantilever deformation.

Tensile and tear testing were carried out using an AI-7000S Universal Material Tester, manufactured by Taiwan Gaotie Company, with a dumbbell specimen at a tensile speed of $500 \mathrm{~mm} / \mathrm{min}$ according to ISO 528:2009. Hardness was tested using a shore A Hardness tester, manufactured by Shanghai Liuling Instrument Factory, according to ISO 23651:2009. Dispersion was studied at $1 \mathrm{~Hz}, 60^{\circ} \mathrm{C}$ using a Rubber Process Analyzer (RPA2000), manufactured by Alpha Technologies Company, USA.

Fillers were treated using ultra-sonic oscillation in alcohol for $20 \mathrm{~min}$ and then collected on 200 mesh copper TEM grids. The collected fillers were observed in the JEM-2100 transmission electron microscope (TEM), manufactured by JEOL Company, Japan. 


\section{Results and Discussion}

\subsection{The Effect of Silica on the Damping Properties of EVM/PLA Blends}

Figure 1 shows the tan $\delta$-T curves of EVM and PLA and EVM/PLA blends. It can be seen in Figure 1 that the peak value of $\tan \delta$ of EVM is 0.98 with corresponding $\mathrm{T}_{\mathrm{g}}$ of $2^{\circ} \mathrm{C}$ and an effective damping temperature range (EDTR) $(\tan \delta>0.3)$ of $27^{\circ} \mathrm{C}$. The peak value of $\tan \delta$ of PLA is 2.19 with corresponding $\mathrm{T}_{\mathrm{g}}$ of $71^{\circ} \mathrm{C}$ and an EDTR of $20^{\circ} \mathrm{C}$. It also can be seen that when EVM was blended with PLA and $30 \mathrm{phr}$ silica, the EDTR of EVM/PLA blend was widened to $81^{\circ} \mathrm{C}$, despite a more reduction of the tan $\delta$ peak values. Comparing the corresponding $\mathrm{T}_{\mathrm{g}}$ of EVM and PLA, the blends' $\mathrm{T}_{\mathrm{g}}$ are not moved closer indicating that EVM 700 is immiscible with PLA.

\subsection{The Effects of Mesoporous Silica/Silica Mixture on the Damping Properties of EVM/PLA Blends}

Figure 2 shows the tan $\delta$-T curves of blends filled with $30 \mathrm{phr}$ silica and mesoporous silica/silica mixture. The EDTR of the blend with $30 \mathrm{phr}$ silica was $81^{\circ} \mathrm{C}$. It can be seen in Figure 2 that the EDTR of the blend filled with mesoporous silica/silica mixture was widened to $86^{\circ} \mathrm{C}$ indicating that mesoporous silica was beneficial as far as improving the damping properties of blends is concerned.

\subsection{The Dispersion of Silica and Mesoporous Silica/Silica in EVM/PLA Blends}

A Payne effect is observed under cyclic loading conditions with small strain amplitudes. Above approximately $10 \%$ strain amplitude, the storage modulus decreases rapidly with increasing amplitude. The storage modulus approaches a lower value at sufficiently large strain amplitudes (roughly 20\%) [16]; $c G^{\prime}=G_{0}^{\prime}-G_{\infty}^{\prime} \quad\left(G_{0}^{\prime}: G^{\prime}\right.$ at

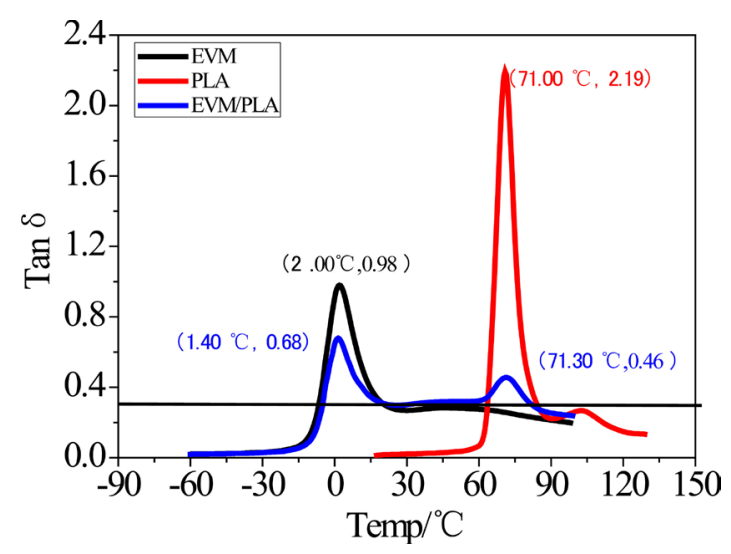

Figure 1. The $\tan \delta$-T curve of EVM and PLA and EVM/PLA blends.

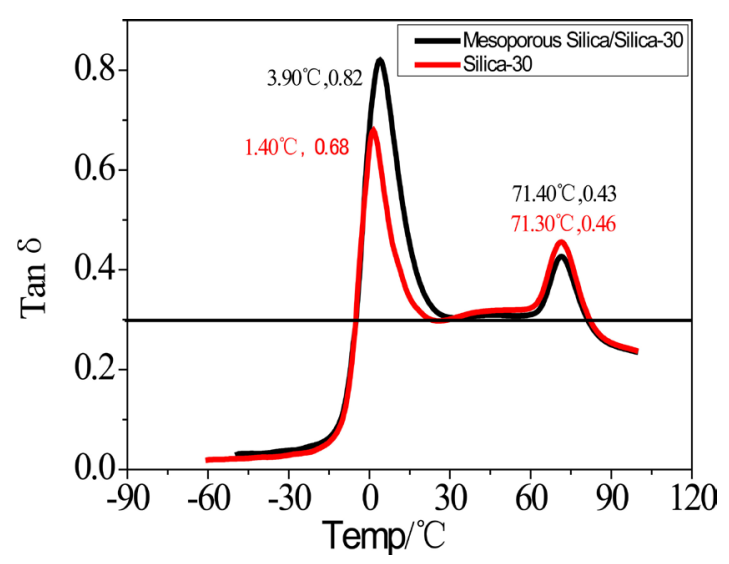

Figure 2. The $\tan \delta$-T curve of silica and mesoporous silica/silica filled EVM/PLA blends. 
small strain amplitude; $G_{\infty}^{\prime}: G^{\prime}$ at large strain amplitude). The larger $\Delta G^{\prime}$ is, the more network volume is formed by filler-filler interactions and the stronger the Payne effect and the poorer the dispersion of the fillers [17].

Figure 3 shows the $G^{\prime}$-strain curves of EVM/PLA filled with different fillers. It can be seen in Figure 3 that the blend with $30 \mathrm{phr}$ silica had a higher $\Delta G^{\prime}$, indicating a poor dispersion of silica in the EVM/PLA blend. This can be attributed to the stronger silica to silica hydrogen-bonding. When mesoporous silica was used, it hindered the agglomeration of silica and $\Delta G^{\prime}$ was reduced. This suggests that a mixture of mesoporous silica and silica should reduce the Payne effect of silica and lead to an improved dispersion.

\subsection{TEM Photographs of Silica and Mesoporous Silica}

TEM photographs of (a) silica 1165 and (b) mesoporous silica are shown in Figure 4. Comparing (a) with (b), it is found that silica has larger primary particles, while mesoporous silica presents a very thin layer with smaller pores. Mesoporous silica has a higher surface area of $650 \mathrm{~m}^{2} / \mathrm{g}$ than the silica employed in this study (165 $\left.\mathrm{m}^{2} / \mathrm{g}\right)$. So friction between mesoporous silica and the matrix is greater. And there could not exist bound rubber because the small porous structure of mesoporous silica restricts the development of bound rubber [18]. Thus, mesoporous silica filled EVM/PLA blends exhibited improved damping performance.

\subsection{Effects of Glass Beads/Silica Mixture on the Damping Properties of EVM/PLA Blend}

The $\tan \delta$-T curves of blends filled with $30 \mathrm{phr}$ silica and filled with glass beads/silica mixture are shown in Figure 5. It should be noted that the value of $\tan \delta$ for the blend filled with $30 \mathrm{phr}$ silica is lower than 0.3 at around $20^{\circ} \mathrm{C}$. When a glass beads/silica mixture was used, the low $\tan \delta$ at around $20^{\circ} \mathrm{C}$ was increased, so the EDTR of blend was widened from $81^{\circ} \mathrm{C}$ to $85^{\circ} \mathrm{C}$.

\subsection{Dispersion of Silica and Glass Beads/Silica Mixtures in EVM/PLA Blends}

Figure 6 shows the $G^{\prime}$-strain curves of EVM/PLA filled with different fillers. It can be seen that the glass beads/silica mixture filled blend has a lower $\Delta G^{\prime}$ than the silica filled blend suggesting that the glass beads hinder the interaction of silica with silica and the dispersion of fillers in the blend was improved.

\subsection{TEM Photographs of Glass Beads}

Figure 7 is a TEM photograph of the glass beads. The glass beads are promising filler for damping materials due to their hollow, spherical structure [19]. It can also be seen that there are some little tiny particles on the surface of the larger bead, which could induce more friction between matrix polymer and the fillers. Thus, the special structure of glass beads may impart an improved damping performance to EVM/PLA blends.

\subsection{Effects of Different Fillers on the Mechanical Properties of EVM/PLA Blends}

Table 1 shows the mechanical properties of blends with different fillers. From Table 1, comparing the data for blends filled with $30 \mathrm{phr}$ silica with those containing mesoporous silica or glass beads, it can be inferred that the

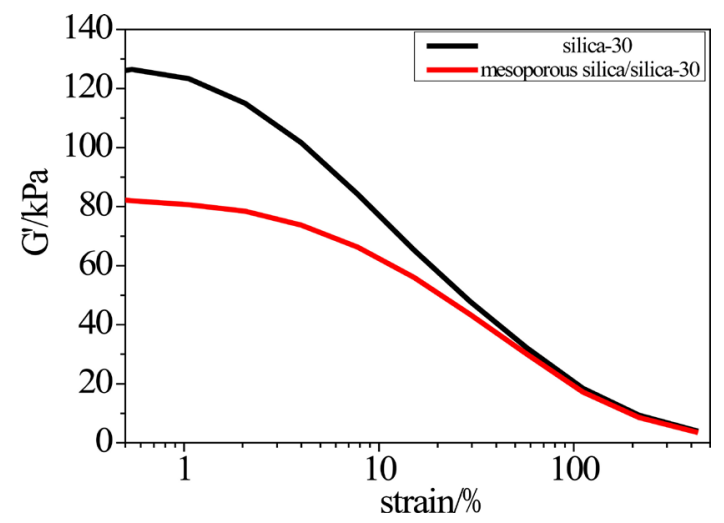

Figure 3. The $G^{\prime}$-strain curve of EVM/PLA filled with silica and a mesoporous silica/silica mixture. 


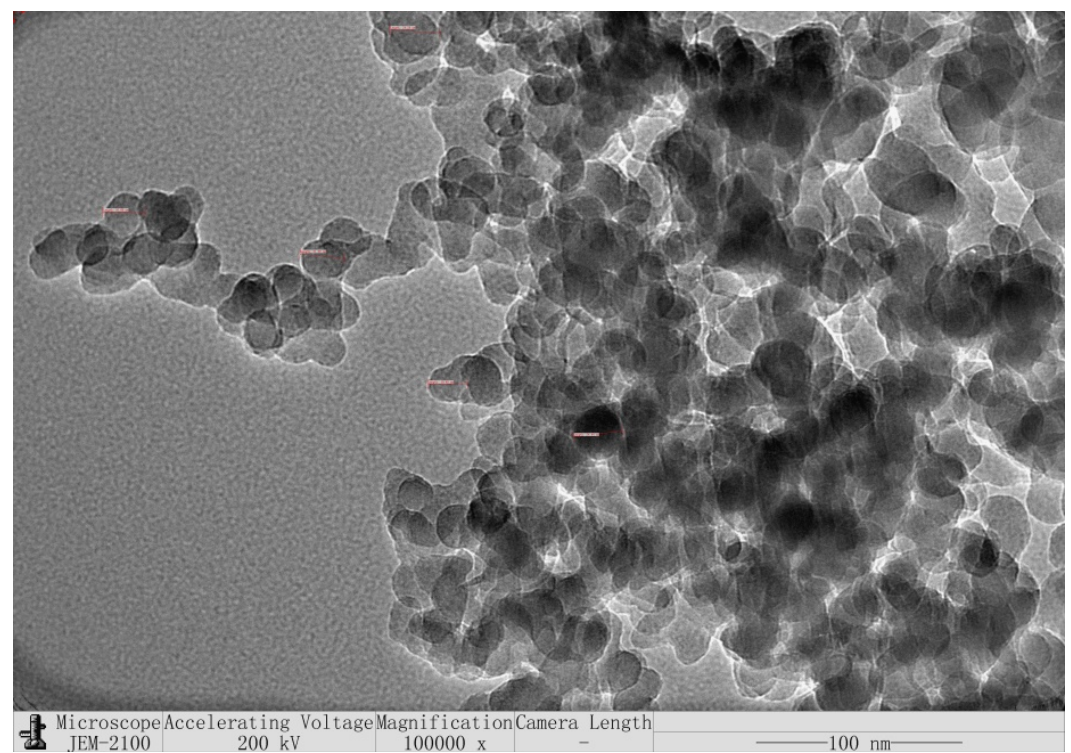

(a)

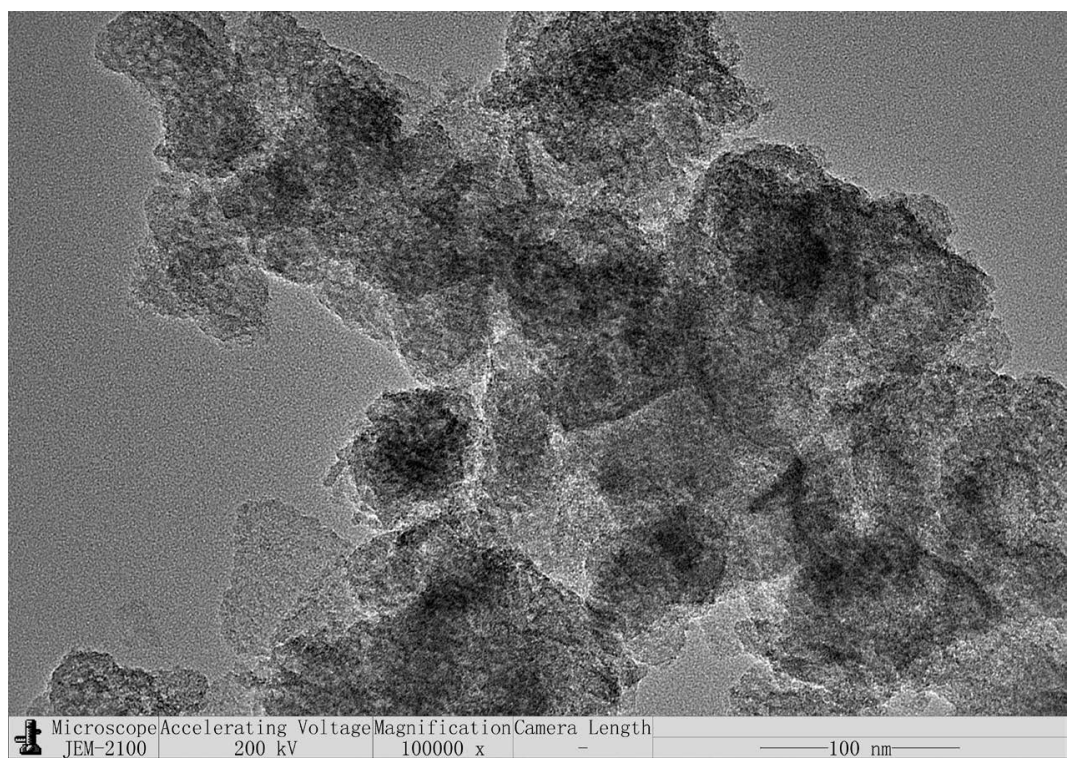

(b)

Figure 4. TEM photographs of (a) silica 1165 and (b) mesoporous silica $(\times 100,000)$.

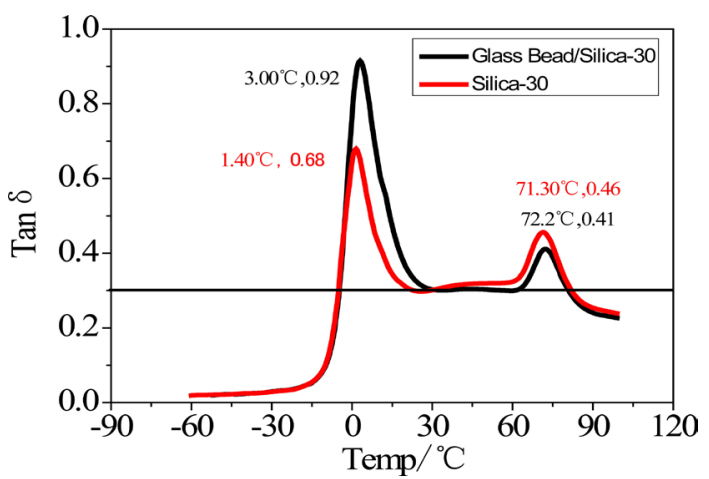

Figure 5. The effects of a glass beads/silica mixture on the damping properties of an EVM/PLA blend. 


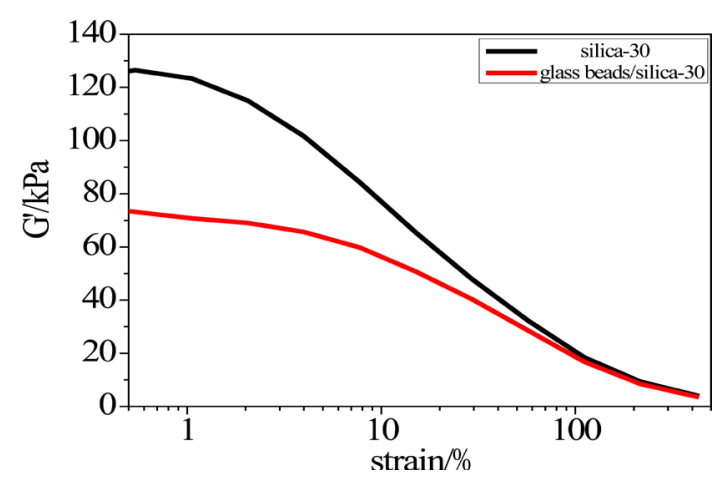

Figure 6. The G'-strain curve of EVM/PLA filled with different fillers.

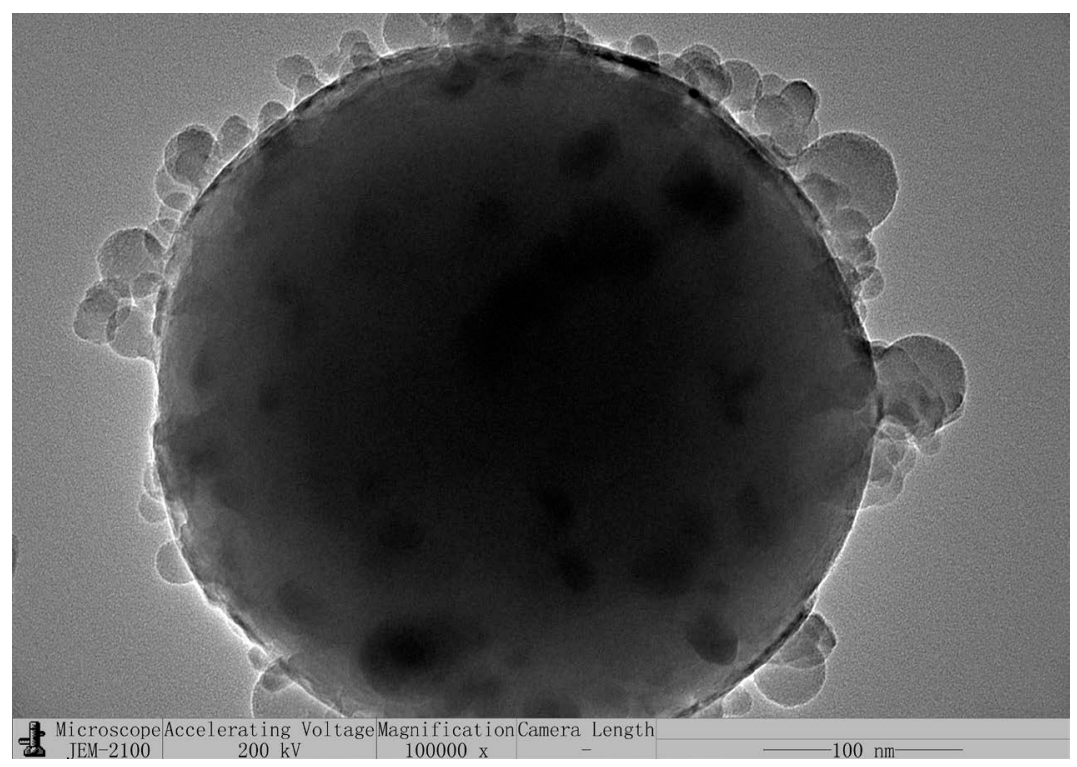

Figure 7. TEM photograph of glass bead $(\times 100,000)$.

Table 1. Mechanical properties of EVM/PLA blends with different fillers.

\begin{tabular}{cccccccc}
\hline Filler & $\begin{array}{c}\text { Modulus at } \\
100 \% / \mathrm{MPa}\end{array}$ & $\begin{array}{c}\text { Modulus at } \\
\text { 300\%/MPa }\end{array}$ & $\begin{array}{c}\text { Tensile } \\
\text { strength/MPa }\end{array}$ & $\begin{array}{c}\text { Elongation at } \\
\text { break/\% }\end{array}$ & $\begin{array}{c}\text { Tear strength } \\
\text { /N/mm }\end{array}$ & $\begin{array}{c}\text { Tension } \\
\text { set/\% }\end{array}$ & $\begin{array}{c}\text { Hardness } \\
\text { /shore A }\end{array}$ \\
\hline $\begin{array}{c}\text { Silica } \\
\text { Mesoporous } \\
\text { silica/silica } \\
\begin{array}{c}\text { Glass } \\
\text { beads/silica }\end{array}\end{array}$ & 4.5 & 10.9 & 20.6 & 496 & 42.9 & 105 & 80 \\
\hline
\end{tabular}

latter had slightly lower tensile strengths, elongation at break and hardness, but that the tension set was considerably decreased. The blend filled with mesoporous silica had slightly higher tear strength and moduli at $100 \%$ and $300 \%$ strain, which might be induced by its special structure. The blends filled with glass beads had the lowest tension set. In conclusion, the best retention of mechanical properties while considerably improving the damping properties is achieved using mesoporous silca/silica blends as filler.

\section{Conclusions}

1) EVM700 was immiscible with PLA; the effective damping temperature range (EDTR) of the blends filled $30 \mathrm{phr}$ silica was widened to $81^{\circ} \mathrm{C}$.

2) The EDTR of EVM/PLA blends filled with mesoporous silica and glass beads were widened to $86^{\circ} \mathrm{C}$ and 
$85^{\circ} \mathrm{C}$, respectively.

3) Mesoporous silica and glass beads mixed with silica could improve the dispersion of fillers in EVM/PLA blends.

4) The blends filled with mesoporous silica or glass beads had a lower tensile strength and elongation at break and a little higher modulus and tear strength. The tension set decreased dramatically. EVM/PLA blends filled with mesoporous silica/silica blends retained reasonable mechanical properties while having improved damping performance.

\section{Acknowledgements}

The authors would like to acknowledge the support of National Natural Science Foundation of China (51273101) and Shandong Science and Technology Program for Universities (J12LA14) without which the work presented in this article would not have been possible.

\section{References}

[1] Wu, C.Y., Wei, C.Y., Guo, W.H. and Wu, C.F. (2008) Dynamic Mechanical Properties of Acrylic Rubber Blended with Phenolic Resin. Journal of Applied Polymer Science, 109, 2065-2070. http://dx.doi.org/10.1002/app.24371

[2] Shi, X.Y., Bi, W.N. and Zhao, S.G. (2011) Study on the Damping of EVM Based Blends. Journal of Applied Polymer Science, 120, 1121-1125. http://dx.doi.org/10.1002/app.33260

[3] Shi, X.Y., Bi, W.N. and Zhao, S.G. (2011) Damping Properties of Blends Based on EVM. Journal of Macromolecular Science, Part B: Physics, 50, 1928-1938. http://dx.doi.org/10.1080/00222348.2011.575029

[4] Yamada, N., Shoji, S., Sasaki, A., Nagatani, A., Yamaguchi, K., Kohjiya, S., et al. (1999) Developments of High Performance Vibration Absorber from Poly(vinyl chloride)/Chlorinated Polyethylene/Epoxidized Natural Rubber Blend. Journal of Applied Polymer Science, 71, 855-863. http://dx.doi.org/10.1002/(SICI)1097-4628(19990207)71:6<855::AID-APP1>3.0.CO;2-V

[5] Fradkin, D.G., Foster, J.N., Sperling, L.H. and Thomas, D.A. (1985) A Quantitative Determination of the Damping Behavior of Acrylic Based Interpenetrating Polymer Networks. Rubber Chemistry and Technology, 59, 255-262. http://dx.doi.org/10.5254/1.3538198

[6] Chen, Q.M., Ge, H.H., Chen, D.Z., He, X.D. and Yu, X.H. (1994) Investigation on Damping Behavior and Morphology of Polyurethane/Polymethacrylates and Polyacrylates Interpenetrating Polymer Networks. Journal of Applied Polymer Science, 54, 1191-1197. http://dx.doi.org/10.1002/app.1994.070540901

[7] Chu, H.-H., Lee, C.-M., Huang, W.G. (2004) Damping of Vinyl Acetate-n-Butyl Acrylate Copolymers. Journal of Applied Polymer Science, 91, 1396-1403. http://dx.doi.org/10.1002/app.13266

[8] Qin, C.L., Tang, D.Y., Cai, J., Cai, W.M., Zhang, J.S. and Qin, M. (2004) Damping Properties and Morphology of Polyurethane/Vinyl Ester Resin Interpenetrating Polymer Network. Materials Chemistry and Physics, 85, 402-409. http://dx.doi.org/10.1016/j.matchemphys.2004.01.019

[9] Xiang, P., Zhao, X.Y., Xiao, D.L., Lu, Y.L. and Zhang, L.Q. (2008) The Structure and Dynamic Properties of Nitrile-Butadiene Rubber/Poly(vinyl chloride)/Hindered Phenol Crosslinked Composites. Journal of Applied Polymer Science, 109, 106-114. http://dx.doi.org/10.1002/app.27337

[10] Wu, C.F., Yamagishi, T., Nakamoto, Y., Ishida, S., Nitta, K. and Kubota, S. (2000) Viscoelastic Properties of an Organic Hybrid of Chlorinated Polyethylene and a Small Molecule. Journal of Polymer Science Part B: Polymer Physics, 38, 1341-1347. http://dx.doi.org/10.1002/(SICI)1099-0488(20000515)38:10<1341::AID-POLB100>3.0.CO;2-R

[11] Li, C., Wu, G.Z., Xiao, F.Y. and Wu, C.F. (2007) Damping Behavior of Sandwich Beam Laminated with CIIR/Petroleum Resins Blends by DMA Measurement. Journal of Applied Polymer Science, 106, 2472-2478. http://dx.doi.org/10.1002/app.25450

[12] Shi, X.Y. and Bi, W.N. (2011) Damping Properties of Ethylene-Vinyl Acetate Rubber/Nitrile Butadiene Rubber Blends. Journal of Macromolecular Science, Part B, 50, 417-426. http://dx.doi.org/10.1080/00222341003772266

[13] Shi, X.Y., Liang, Y.C., Zhang, P. and Zhao, S.G. (2006) Properties of Thermoplastic Polyurethane and Ethylene-Vinyl Acetate Copolymer Blends. Synthetic Rubber Industry, 29, 458-461.

[14] Shi, X.Y., Bi, W.N. and Zhao, S.G. (2011) DMA Analysis of the Damping of Ethylene-Vinyl Acetate/Acrylonitrile Butadiene Rubber Blends. Journal of Applied Polymer Science, 124, 2234-2239. http://dx.doi.org/10.1002/app.35301

[15] Semba, T., Kitagawa, K., Ishiaku, U.S. and Hamada, H. (2006) The Effect of Crosslinking on the Mechanical Properties of Polylactic Acid/Polycaprolactone Blends. Journal of Applied Polymer Science, 101, 1816-1825. 
http://dx.doi.org/10.1002/app.23589

[16] Chandrasekaran, V.C. (2010) Rubber as a Construction Material for Corrosion Protection. John Wiley and Sons, Inc., Hoboken, 83-84. http://dx.doi.org/10.1002/9780470893197

[17] Niedermeier, W., Fröhlich, J. and Luginsland, H.-D. (2002) Reinforcement Mechanism in the Rubber Matrix by Active Fillers. Kautsch. GummiKunstst, 55, 356-366.

[18] Gou, C.P., Chen, E.F. and Ma, C. (2012) Research Progress in Effect of Inorganic Fillers on Properties of Polyurethane Damping Materials. Journal of Liaoning Chemical Industries, 41, 475-480.

[19] Zhao, X.P. (2008) Preparation of Casting Polyurethane Elastomer Composites and Their Properties. Dissertation for the Degree of Master Engineering, Harbin Engineering University, Harbin, 48-54. 